\title{
MICROSCOPIC TRAFFIC SIMULATION USING VANETS TRAFFIC SIMULATOR VISSIM
}

\author{
Namit Gupta ${ }^{1}$, Sachin singh ${ }^{2}$, Mohan Vishal Gupta ${ }^{3}$ \\ Department of Computer Science, CCSIT, Teerthanker Mahaveer University, Moradabad \\ Department of Computer Science, CCSIT, Teerthanker Mahaveer University, Moradabad
}

\begin{abstract}
The growth of motorization on highways in India has so far been of 2-wheeler and 3-wheeler variety, imposing negative impacts on both bus and car transport. It has also resulted in highly heterogeneous traffic conditions with varying static and dynamic characteristics of different types of vehicles. Since system is too complex and analyses needs microscopic simulation model. Stochastic models have better quality than deterministic and microscopic nature of traffic simulation delivers psycho-physical behavior of vehicular interaction. Present work signifies the applicability of VANET Traffic simulator VISSM. Therefore, present study makes the use of traffic simulation to understand the nature of mixed traffic by discrete, stochastic and time-step based analysis.
\end{abstract}

Keywords: Microscopic Traffic, VANET, VISSIM, Weideman model, Speed Characteristics

\section{INTRODUCTION}

Since, development in the area of computer science and simulation in early 1950's and 1960's has been very tremendous and it is now an everyday tool for practitioners and researchers in all fields of the profession. Previous literatures regarding roadway traffic data analysis and simulation in mixed traffic conditions in India has been considered for present study. Research guidelines regarding speed data analysis have also been considered in this study. This study is tested the applicability of a microscopic traffic simulation VISSIM which is mostly used in US and Germany, for modeling traffic flow operation. System Architecture of VISSIM is shown in Figure1. Present study uses VISSIM for simulating mixed traffic condition as observed in field data. The present simulation analysis is concentrated only on speed characteristics of different vehicles observed on four-lane highway. It also covers the concept and logics used by VISSIM for simulating a road network where the movement of individual vehicles has been tracked. Speed profiles of different vehicles were created using simulated data and were compared with field data also.

VISSIM is a German acronym for "Traffic in Towns Simulation", the name is derived from "VerkehrInStädtenSIMulationsmodel". VISSIM traffic simulation tool has ability to evaluate all vehicular as well as rail-road traffic.

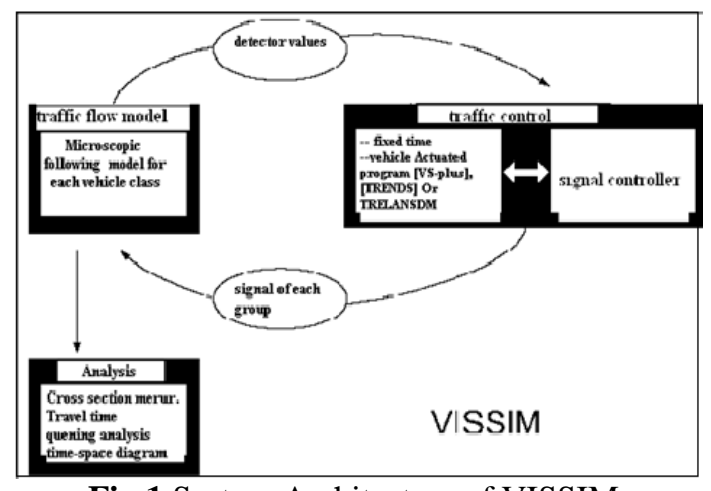

Fig.1 System Architecture of VISSIM

Car-following found one of the basic questions of traffic flow theory and simulation for the intersection analysis, and still under active analysis after almost 40 years from the first trials (McDonald et al., 1998). During 1997 and 1998, Parsons Transportation Group (PTG) conducted a study for the Long Island Rail Railroad in New York City which included a detailed evaluation of VISSIM, CORSIM, WATSIM, and TRANSIM. As a result, VISSIM was selected for that project based on its overall ability to model transit, automobile traffic, complex traffic and transit geometries, and complex user defined traffic control strategies such as preemption and priority (Brian et al. 2000). Bloomberg and Dale (2000) compared VISSIM and CORSIM in a congested network in Seattle, Washington DC. VISSIM rout-choice travel times were compared with the CORSIM results by using the paired t-test to determine whether the difference between the two models was significant. Fellendorf and Vortisch (2001) performed an analysis of the car-following model for Germen and US and validated VISSIM model for various real world situations in Germany and abroad. Authors introduced driver behavior parameter calibration techniques by using range of time-step from 0.1 to 1 .Adjusting time-step in comparative simulation 
they modeled the car-following behavior of drivers by considering four driving modes. Velmurugan et al. (2010) developed Speed-flow equations and determined the capacitythrough simulation for 4-lane, 6-lane and 8-lane divided high speed corridors under heterogeneous condition. Authors validated the model for volume, speed and lane change criteria. They also compared the traditional method and the results of microscopic simulation method through VISSIM with lane change and without lane change behavior.

\section{WEIDEMANAPPROACH}

The basic concept of microscopic simulation model introduced by Wiedemann (1974) was to describe the quality and efficiency of the simulation system in modeling human driving behavior. The actual traffic is modeled on unidirectional roads, which can be both for interurban roads like highway or urban roads with physical separation between the lanes for different direction. This approach explained car-following model where the longitudinal vehicle movement is influenced by the vehicle in front in the same lane. Extensive investigations were undertaken by TODOSIEV (1963), MICHAELS (1965) and HOEFS (1972) to find the limits of human perception thresholds in car following process. These investigations form the basis of the model developed by Wiedemann in 1974. The continues work of Wiedemann provided two driver behavior models named as Wiedemann 74 model and Wiedemann 99 model. The Wiedemann 99 model is a more complex representation of the car following model as it contain ten calibration components. This algorithm was specifically developed for application to freeway and expressway conditions.

\section{SIMULATION DATA}

The precise input data required by microscopic simulation model vary with software and the specific modeling application which is defined by study objectives and scope. Any microscopic simulation model requires the basic types of input data as shown in Table 1.

Table 1: Data Source for Microscopic Analysis

\begin{tabular}{|l|}
\hline Data Source \\
\hline Road Geometry Data \\
\hline Demand Data \\
\hline Traffic Control Data \\
\hline Public Transport \\
Detail \\
\hline On-Street Parking \\
\hline Calibration Data \\
\hline
\end{tabular}

\section{FIELDDATA}

It is important for the modeler to observe existing operation on site during the time period which is being simulated. For present study, a midblock section of four-lane Delhi-Hapur highway was selected which has $7 \mathrm{~m}$ road width in each direction with more than $1.8 \mathrm{~m}$ wide gravel shoulder on either side. The data were collected by video graphic method. Speed was measured by using a trap length of $30 \mathrm{~m}$ made on the road using white self-adhesive tape. The day of video data collection was sunny and the traffic was operated under the normal condition. Five type of vehicle have been observed on highway and information regarding vehicle types is given below in Table

Table 2: information regarding vehicle types

\begin{tabular}{|l|l|l|l|}
\hline \multirow{2}{*}{$\begin{array}{l}\text { Vehicle } \\
\text { Class }\end{array}$} & \multicolumn{2}{|l|}{$\begin{array}{l}\text { Average } \\
\text { Dimension }\end{array}$} & $\begin{array}{l}\text { Projected } \\
\text { Rectangular } \\
\text { Area (m2) }\end{array}$ \\
\cline { 2 - 4 } & $\begin{array}{l}\text { Length } \\
\text { (m) }\end{array}$ & $\begin{array}{l}\text { Width } \\
(\mathbf{m})\end{array}$ & \\
\hline Car & 3.72 & 1.44 & 5.36 \\
\hline Truck & 10.1 & 2.43 & 24.54 \\
\hline Bus & 10.1 & 2.43 & 24.54 \\
\hline 3wheeler & 3.2 & 1.4 & 4.48 \\
\hline 2 wheeler & 1.87 & 0.64 & 1.20 \\
\hline
\end{tabular}

\section{SIMULATEDRESULTSANDDISCUSSION}

Simulation runs were performed after giving all the required inputs to VISSIM. Simulated speed of each vehicle types was measured from the travel time section created in VISSIM roadway link. Simulated speed was calculated from the travel time taken by a vehicle to cross the $30 \mathrm{~m}$ traplength in VISSIM. Finally, simulated speed data was transferred to excel work sheet for further analysis. Speed is considered as random variable and generally follows a normal probability distribution. Speed data obtained from simulation was separately analyzed for each vehicle types. Speed frequency was measured and cumulative speed percentile was calculated. Speed frequency distribution curve (cumulative speed profiles) through field and simulation of cars are discussed here in the paper. Speed parameters such as average speed, maximum speed and minimum speed were evaluated for each vehicle type simulated in VISSIM. The summary of speed distribution parameters is given in Table 3.

Table 3: Speed Parameters through Simulation Data

\begin{tabular}{|l|l|l|l|l|l|}
\hline \multirow{2}{*}{$\begin{array}{l}\text { Parameed } \\
\text { Maximum }\end{array}$} & \multicolumn{5}{|l|}{ Four-Lane Highway } \\
\cline { 2 - 6 } & Speed (km/h) \\
\cline { 2 - 6 } & Car & Truck & Bus & $\mathbf{3 W}$ & $\mathbf{2 W}$ \\
\hline Minimum & 39.2 & 65.3 & 70.2 & 50.3 & 74.6 \\
\hline Average & 58.0 & 48.3 & 35.2 & 32.5 & 38.6 \\
\hline
\end{tabular}

Speed of each vehicle class obtained from field observation was assigned to VISSIM for simulation. Simulation run was performed and simulated speed of each vehicle type was obtained todevelop speed profiles. To check the performance of VISSIM for simulating field observedtraffic condition, a comparison between field speed and simulated speed data was made for only cars. The speed profiles of car vehicle type developed from field as well as simulation were shown together in Figure 2 with comparison of average speed in field and simulation of all the vehicle class shown in Figure. 


\section{REFERENCES}

[1] Bloomberg, L. and Dale, J. (2000). Comparision of VISSIM and CORSIM traffic simulation models on

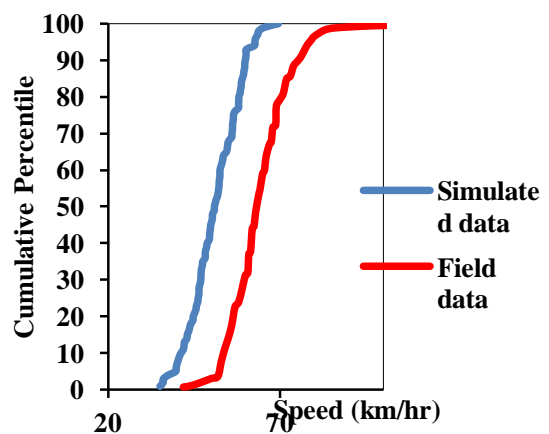

Fig.2 Comparisons of Speed Profiles of Cars

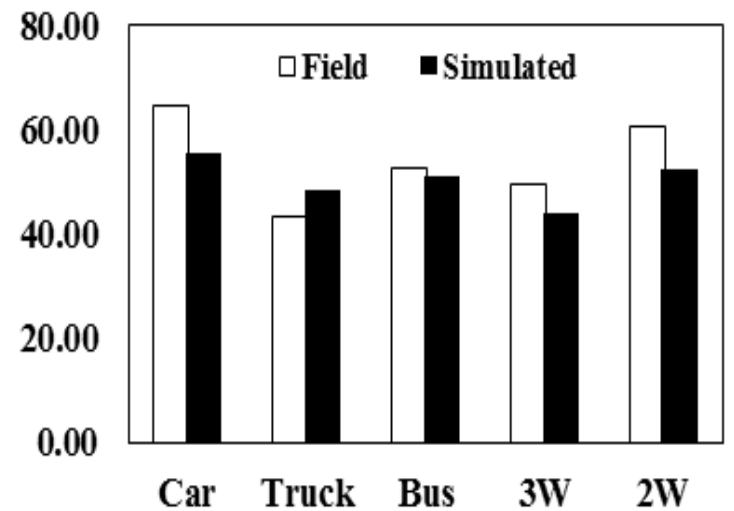

Fig.3 Comparison of Field Observed and Simulated Average Speed

\section{CONCLUSIONS}

The following conclusions can be drawn from the present study.

Speed data obtained through simulated outputs were compared with field observed speed. The comparison of speed profiles provides the information that the VISSIM is overestimating speed of all vehicles excluding the cars type vehicle and is failed to reflect the traffic conditions as observed in the field.

The comparison of average speed of each vehicle type was made and it shows that there is a significant difference between simulated and field average speed of all vehicles. Therefore, results obtained from VISSIM are not satisfactory.

The present study concludes that the VISSIM is capable to analyze the heterogeneous traffic conditions as seen in India but after some degree of calibration.

The VISSIM is developed in Germany and its parameters of driver behavior have some default values provided by the model developers. Therefore, it is required to calibrate and validate the VISSIM's parameters for the traffic condition as observed in the field. a congested network, Transport Research Record1727, TRB, National Research Council, Washington DC, pp. 52-60.

[2] Dowling, R., Skabardonis, A, Halkias, J., Mc Hale, G. and Grant, Z. (2004). Guidelines for calibration of microsimulationmodels, Transport Research Record 1876, TRB,

[3] National Research Council, Washington DC, pp. 19.microsimulationmodels, Transport Research Record 1876, TRB, National Research Council, Washington DC, pp. 1-9.

[4] Farouki, O.T. and Nixon, W.T. (1976). The effect of width of suburban roads on mean free speed of cars, Traffic Engineering and Control, Vol. 17 (12), pp. 518-520.

[5] ArpanMehar, Satish Chandra and, S. Velmurugan (2012). "Passenger Car Units at Different Levels of Service for Capacity Analysis of Multilane Interurban Highways in India," J. Transp. Eng., 140(1), 81-88.

[6] VISSIM: User's Manual (2009), version 5.1, Planning Transport Verkehr (PTV) AG, Karlsruhe, Germany

[7] Velmurugan, S., Errampalli, M., Ravinder, K., Sitaramanjaneyulu, K. (2010). Critical evalution of roadway capacity of multilane high speed corridors under heterogeneous traffic condition through traditional and microscopic simulation model, Journal of Indian Roads Congress, No.566, pp. 253-264.

[8] ArpanMehar, Satish Chandra and S. Velmurugan (2013) "Speed and Acceleration Characteristics of Different Types of Vehicles on Multi-Lane Highways" European Transport $\backslash$ TrasportiEurope 